Nigel Fabb

\title{
Poetic form as meaning in Walt Whitman's Leaves of Grass
}

revised draft version of 2012, for Journal of Literary Semantics , to appear in issue 41:2

\section{Poetic form}

Kinds of poetic form include the division of a text into lines, the counting of syllables, control over rhythm, sound patterning such as rhyme or alliteration, and parallelism. Poetic form can hold of a text by virtue of its being a meaning of the text (Fabb 2002: 57). More precisely, poetic form can hold of a text just by virtue of its being the content of an implicature, a thought about the text formulated by its reader, for which the text provides evidence. Such an implicature might be "this section of text is a line", or "these two parts of a text are parallel". Fabb (2002) argues that this is one of two possible ways in which poetic form can hold of a text, and calls this type of implicated form "attributed form". The other way in which poetic form can hold is as a result of specialized and psychologically covert computations, similar to the specialized computations which characterize the phonological or syntactic operations of linguistic cognition, thereby producing regular forms and regular relations between forms in a language. These are "inherent forms" of a text; many kinds of linguistic form are inherent in this sense, and one example of inherent poetic form may be the metrical form of a text which may be constructed by phonology-like psychological processes. In this paper, I argue that in Walt Whitman's Leaves of Grass all the poetic forms - even the lineation itself - hold as implicatures which are evidenced by the text (kinds of attributed form), and do not hold inherently as a result of special psychological computations (not kinds of inherent form). I show that because poetic form is attributed rather than inherent in Leaves of Grass, this has consequences both for the ways in which the poetic forms relate to one another, and for the ways in which the poetic forms provide evidence for the text's other meanings.

Inherent and attributed forms can appear to be similar; for example "sentence" is a form both for linguistic theory where it is a type of inherent form theorized as holding at some psychological level, characterized by having certain often covert formal properties. But "sentence" is also a form for pedagogic grammar, where it is a name for a section of text, a type of attributed form characterized overtly by punctuation and usually by various prescriptive rules. The linguistic theory's inherent sentence and the pedagogic grammar's attributed sentence will often be ways of describing aspects of the same verbal material, though not always. Though there are similarities between them, inherent and attributed forms are fundamentally different in kind. As readers, the inherent forms of the text we read exist for us as part of our linguistic cognition, below the level of consciousness. In contrast, the attributed forms of the text we read exist for us only as the content of inferences which we draw about the text, based on evidence provided by the text. The attributed forms of a 
text are thus meanings of the text, which, if communicated by the author, are implicatures (intended implications) of the text.

Inherent forms should be understood as being produced by psychological operations below the level of consciousness, analogous to the way in which linguistic (e.g., phonological) form is produced. Generative approaches to poetry have looked for ways of showing that inherent poetic forms can hold in the same way that linguistic forms hold (Fabb 1997; Fabb and Halle 2008; Golston and Riad 2000; Hanson and Kiparsky 1996; Hayes and Moore-Cantwell 2011). These generative approaches explain the presence of forms such as meter or rhyme by generating them by rules or conditions similar to those in phonology. Evidence in favour of this is that the poetic form can only be explained by citing formal elements which are not accessible to consciousness (such as underlying phonological forms). Further evidence is that the poetic form holds in ways which are not obvious to the poets who compose with it, again suggesting the operation of rules or conditions below the level of consciousness. A third piece of evidence is that the poetic form is governed by universal formal generalizations, which could only arise if the poetic form is produced by specialised computations. For example, Fabb (1999), looking at a range of poetries in different languages, argues that alliteration is always subject to a covert constraint which does not apply to rhyme: alliterating elements must be adjacent, unlike rhyme, so that for example the ABAB patterns which are common rhyme schemes never appear as alliteration schemes. Universal constraints of this kind, which have no clear functional cause, would be difficult to explain for attributed form, which should be much more freely manipulable.

The present paper argues that the various poetic forms of Walt Whitman's Leaves of Grass are all attributed, and thus that the study of this kind of form comes under the remit of pragmatics. That is, all the forms hold as attributed forms: they hold of the text to the extent that they are evidenced, they provide mutually reinforcing evidence, and they are subject to loose rather than strict generalizations. The formal status of any kind of form - as either inherent or attributed - is open to debate or discussion or analysis; any text might in principle manifest either inherent or attributed forms. Whitman's radical practice offers us new formal possibilities and formal interactions, which thus can be used to explore the criteria for making a distinction between kinds of form. In Whitman's case we can further see how attributed form can be symbolic form: the form of the text itself communicates further meanings (the mix of the democratic, the Egyptian, and other meanings which the text expresses).

\section{The poetic forms of Leaves of Grass}

Many of the poetic forms of Leaves of Grass can be illustrated by the following five lines which form a stanza of one of the component poems of the book, reproduced here as closely as possible to copy the layout (e.g., line-breaks) on page 67 of the first (1855) edition. 
The sky continues beautiful .... the pleasure of men with women shall never be sated .. nor the pleasure of women with men .. nor the pleasure from poems;

The domestic joys, the daily housework or business, the building of houses - they are not phantasms .. they have weight and form and location;

The farms and profits and crops .. the markets and wages and government .. they also are not phantasms;

The difference between sin and goodness is no apparition;

The earth is not an echo .... man and his life and all the things of his life are wellconsidered.

\section{[**note to typesetter - please keep these lines with line-breaks exactly as laid out, as this reproduces the original typesetting of the poem]}

Here we see various poetic forms. The most obvious is the line. Next, it has been argued that the poem is divided into 'rhetorical groups'. Third, there is parallelism between the parts. Fourth, there are small rhythmic sequences. IN this section of the paper I consider each of these in turn and argue that they are inherent rather than inherent. I conclude by commenting on the unusual lineinternal punctuation, in particular two dots, four dots and a dash, which have relevance for the form of the text.

\section{The line}

A text can be divided into lines, or not divided into lines: this is in essence the distinction between verse and prose. This does not depend just on the way the text is laid out on the page (or on how it is performed), but is more fundamentally a matter of how the text is organized relative to other poetic forms. Beowulf and the older Greek texts survive in their earliest written forms as prose but are nevertheless verse, as can be demonstrated by the fact that once understood as organized into lines we can formulate generalizations about syllable counting, rhythm, alliteration, and word boundary placement. The fact that these texts were presented as prose at one point shows us that a text can be inherently in lines but not have lines attributed to it. Similarly, a text can be presented as in lines - any prose text can be randomly divided and so presented on the page - but the lines have no inherent formal status as lines. Thus there must be a distinction between the line as an inherent form and the line as an attributed form. Consider as a further example Paradise Lost, which Samuel Johnson described as "verse only to the eye", which we can interpret as saying that lineation is attributed form in the poem. But Johnson was wrong, because if the poem is written out as prose it still retains formal characteristics which show that it is inherently lineated: for example, every tenth syllable is word-final, as we would expect if the poem is in ten-syllable lines and words cannot be split across a line boundary.

How does one decide whether lineation is inherent? Lineation exploits those aspects of language which are sequential (e.g., language is spoken in time, which is sequential, or written as a sequence of words on a page), and creates sub-sequences from the more general sequence. Those sub-sequences are lines. Further, the line must be subject to generalizations which are not directly dependent on linguistic generalizations or form: written prose divides text into sub-sequences separated by punctuation (full stop or period) but these subsequences are dependent on the linguistic form of the sentence. Lineation does 
not mirror linguistic form in this way, but instead is subject to generalizations which though they refer to linguistic form are additionally imposed on the linguistic form: rhyme can define line boundaries, and refers to phonological form, but it is an imposition on or organization of linguistic form. Where lineation is not subject to these types of generalization, we must treat it as an attributed form of the text, which in written poetry is often reflected in layout on the page.

I suggest that most of Whitman's lineation is attributed (though there are occasional examples of inherent lineation, as in the following example which are lines written in iambic pentameter (Whitman 1881: 296).

Out from behind this bending rough-cut mask,

These lights and shades, this drama of the whole,

Like all iambic pentameter lines, these lines are subject to subtle generalizations, which can loosely be summarized by saying that there are ten syllables in each line, and a stressed syllable within a polysyllabic word must be even-numbered. The standard claim within generative poetics is that such generalizations are best expressed by a specialized set of rules and conditions, analogous to those which govern the phonology of language, and that these generalizations must be stated over the line as a distinct unit which must thus be similarly real and stable for the psychological representation, and thus the line is a type of inherent form.

I will argue that, while there are occasional eruptions of inherent lineation in the poem, in most of Leaves of Grass the line is attributed rather than inherent. There are three aspects to any line, which I consider in turn: the line is a domain within which other forms may hold, it is a section of text with edges, and it is a section of text which is similar to or related to other adjacent sections of text. Consider first the line as a domain within which other forms may hold. In metrical verse the line is a domain within which syllables are counted: each line of iambic pentameter is ten syllables long. In many meters there is also a characteristic rhythm which takes the whole line as a domain: iambic pentameter has a characteristic rhythm in which even numbered syllables tend to be stressed. Leaves of Grass is not metrical because there is no counting of syllables into the line, but the line is a domain in other ways. It is a domain within which parallelism holds between phrases and words; it is a domain which can be divided into "rhetorical groups"; and it is a domain within which certain kinds of punctuation are exclusively used: sequences of dots, and a dash, are found only line-internally. These types of form both provide evidence for the line, and because loose generalizations relate them to the line as a domain, they rely on the line as a domain within which they become manifest.

Next, consider the edges of the line, which in metrical verse can be a place for rhyme or alliteration or a final rhythmic cadence. As Allen (1933: 499) notes, in Leaves of Grass, it is common to find exact repetition of words or phrases at the beginning of a line (epanaphora), and sometimes also at the end (epanalepsis). Though they are not metrical, the lines may also end on a fairly regular rhythm, which Hollis (1983: 36) calls a cursus. Some punctuation marks are found only line-finally (the period and semi-colon). All these kinds of form both provide evidence for the line, and depend on the line to provide a place where they can regularly appear: the more regular the appearance of a form, the better the 
evidence that it exists. The occasional presence of these forms provides evidence for the line as an attributed form, but the fact that they are not consistently present (and also the fact that they are not themselves inherent forms) mitigates against the line being an inherent form.

Finally, when a section of text is a line it is usually adjacent to another section of text which is a line. This is a cumulative reinforcement: if one section of text is a line then the adjacent section is, which in turn reinforces the evidence that the first section is a line. (What makes this non-circular is that there is always other evidence as well.) The fact that the line is defined as a form both by its internal structure and by its relation to other lines relates to what Mitchell (1969: 1610) calls the "paradox of the line" in Leaves of Grass: "Everything begins with the paradox of the line, its existence as a separate end-stopped unit within the poem, section or stanza, its simultaneous independence and dependence".

When an early reviewer calls Leaves of Grass a "singular prose poem" (anon 1856), we can interpret him as saying that the text is in attributed but not inherent lines; the same is true for Saintsbury who says that "no small part of the 'Verse' - he calls it 'verse' himself - if printed straight on, would be indistinguishable from no small part of the prose (Democratic Vistas, etc.) which is so printed" (Saintsbury 1910: 491). Leaves of Grass is certainly in attributed lines, but it is worth noting that attributed lineation may coincide with inherent lineation: Shakespeare's sonnets are in attributed lines (explicitly presented and recognized as lines) but at the same time also in inherent lines. We have seen, however, reasons for thinking that the attributed lineation of Leaves of Grass does not overlie an inherent lineation. The line interacts with other forms - the rhythmic groups, rhetorical groups, parallelisms and punctuation sequences, which are subject to generalizations stated in terms of the line. However, all of these poetic forms are themselves attributed and not inherent, and have a loose rather than strict relation to the line. This further suggests that the line is itself an attributed rather than an inherent form, because inherent form can only be evidenced by other inherent forms, and there appear to be no inherent forms which provide evidence for the existence of the line. These two facts suggest that the line in turn is an attributed rather than an inherent form in Leaves of Grass. That is, though the text is visibly in lines, the lineation of the text is attributed to the text by pragmatic processes, rather than being an inherent fact of the text. The fact that the line is an attributed poetic form enables it to be a symbolic form: the meaning that "the text is in lines" is the source of further meanings about the text, as we will see.

\section{Rhetorical groups}

Mitchell (1969: 1607), says that "the key to the scansion of Whitman's poetry is the caesura" which divides the text into what he calls "rhetorical groups" which have no consistent grammatical form. Thus he says that in the following passage "Failing to fetch me at first // keep encouraged" is a division of a line into two rhetorical groups, as is the next line "Missing me in one place // search another" (Whitman 1855: 56). 
Failing to fetch me at first keep encouraged,

Missing me one place search another,

I stop some where waiting for you

Rhetorical groups are not identical with any other grouping: they have no consistent form, they are not always involved in parallelism, and they need not be separated by punctuation. Rhetorical groups both do and do not relate to the line, which Mitchell attributes to what he calls the "paradoxical nature of the line", as noted above: they are contained within lines, but they also form patterns irrespective of line boundaries which develop over the text as a whole, e.g., patterns of increasing length, thus making formal variation possible. Any type of formal variation can produce an interpretive consequence: in Leaves of Grass patterns of variation in size can provide evidence for interpretation, particularly if they form a shape such as parabola (getting longer and then shorter within a section of text) or are progressively longer within a section of text. In conclusion, we must see the rhetorical group (and the associated notion of caesura in this poem) as an attributed poetic form. It has no consistent definition, and is identified partly on the basis of the explicit function of the lines: form is thus a reflection or interpretation of function, and thus a type of attributed form.

\section{Parallelism}

Syntactic parallelism in Leaves of Grass has been extensively discussed by Allen (1933) and Warren (1990); this is a type of poetic form which arises when two or more sequences of words are both in similar syntactic structures and have related (similar or opposed) meanings. Syntactic parallelism is widespread in Leaves of Grass. In Figure 1 the previously quoted text is arranged to align parallel sections vertically, to illustrate the parallelism ([1] [2] etc. indicate ends of lines).

Figure 1 


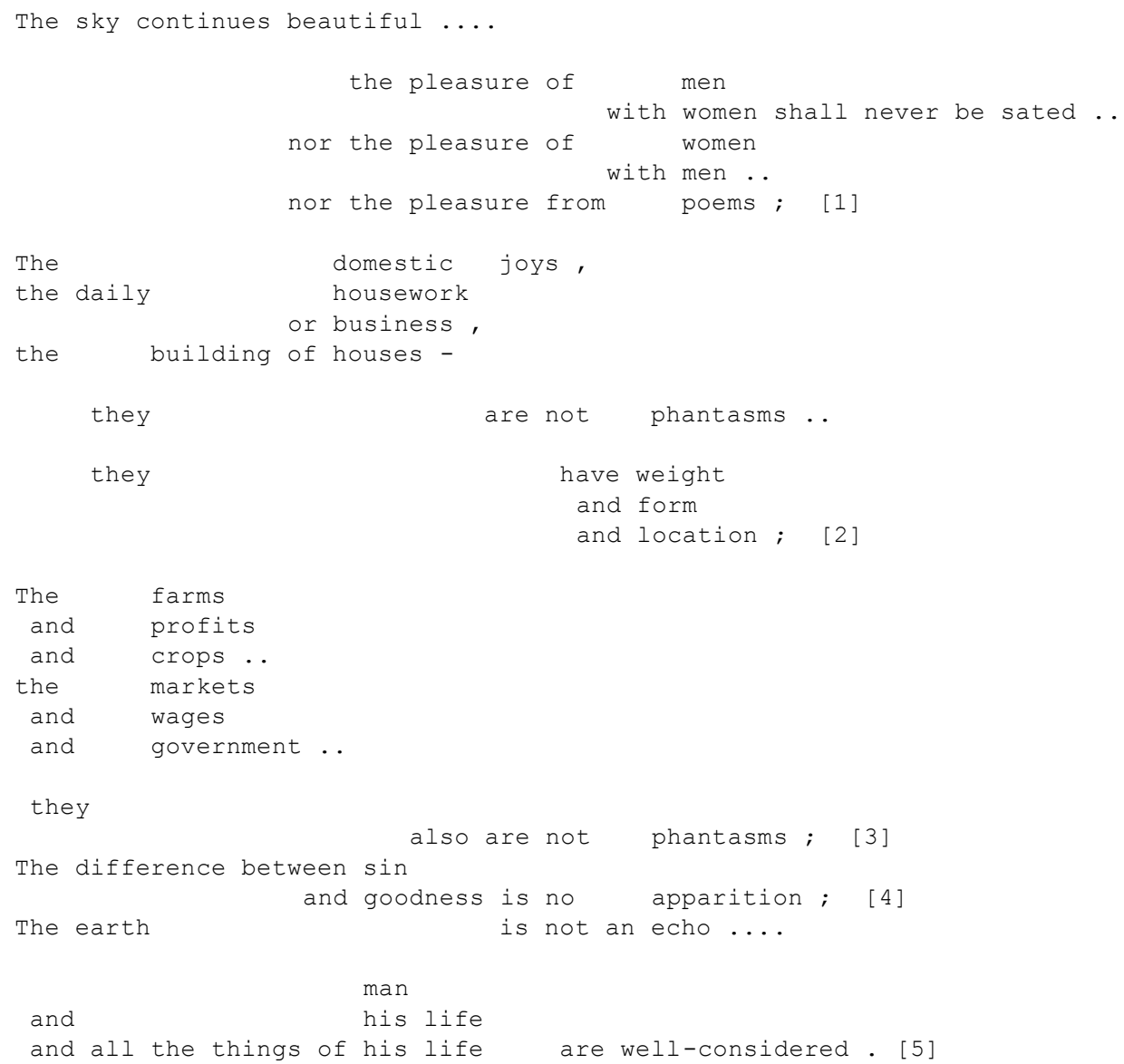

[**note to typesetter - please keep these lines with vertical alignments
exactly as laid out]

As Allen (1933) notes, Whitman's use of parallelism resembles the parallelism in the English translation of the Bible, though Whitman has longer and less repetitive sequences. Often all the parts of a parallelism are contained within a line, thus showing that there is some relation between the form of parallelism and the form of the line. But this is also sometimes violated in unsystematic ways as for example the sequence formed by the distinct sections "not phantasms... not phantasms... no apparition... not an echo" which starts midway between the second line, comes at the end of the third and fourth lines, and then the beginning of the fifth. Thus it is possible to state a generalization about the relation between parallelism and the line, which is that the location of parallelistic sequences is sensitive to the presence of line boundaries. However, these generalizations are not strictly obeyed. The syntactic structures and words from which parallelisms are formed are examples of inherent linguistic form, and so parallelism is derived from the inherent form of the text. However, the existence of a relationship of similarity or significant difference between the linguistic forms is best treated as attributed because similarities are attributed to sets of words rather than being an inherent fact about them (e.g., based on their lexical semantics). For example figure 1 treats "weight", "form" and "location" as related terms, but outside this text we would probably not put them together 
into a set of related terms. In context, both the syntactic structure and the general expectation of parallelism encourage us to interpret them as related terms. In working out parallelisms it is also common to find that there are alternative ways of understanding the parallelistic structure, and that some parallelisms seem more clear than others. These considerations all fit with parallelism being an attributed poetic form. It is worth noting in conclusion that there are traditions such as that of Quiché ritual speech (Norman 1980) in which parallelism is very systematically coded both syntactically and lexically, which demonstrates that though parallelism in Leaves of Grass is a type of attributed form, in other traditions parallelism can in principle be an inherent form.

\section{Small rhythmic sequences}

Allen (1933: 502) notes that where syntactic parallelism is found in Leaves of Grass, there is often an associated rhythmic parallelism because similar syntactic structures can have similar rhythms. These are attributed poetic forms, for two reasons: the parallelisms on which they are based are themselves attributed, and the rhythmic structures are not identical but must be judged to be the same, as Allen acknowledges when he says that "Naturally some are easier to diagram than others". The presence of rhythmic patterns is thus observer-dependent, which is a sign of its being an attributed form.

Hollis (1983) identifies the cursus as a type of rhythmic structure in Leaves of Grass. The cursus is usually a sequence of syllables in a stress-unstressunstress or stress-unstress pattern, repeated several times and possibly ending on a stressed syllable, but with the longer sequence never following the shorter so that the stressed syllables tend to get closer towards the end (this rhythm resembles a loose trochaic meter as described by Fabb and Halle 2008: 247). The cursus comes at the end of what Croll (1919) in his account of English religious prose calls "a sense unit" which itself appears to be a type of attributed form. A cursus in our extract is "pleasure of women with men" (stressed syllables 7-4-1, counting from right to left), and another is "pleasure from poems" (stressed syllables 5-2). Though the cursus seems to be based on the phonology of the text, it is clear that even these phonological characteristics are attributed rather than inherent. Croll (1919: 45) hears the first stressed syllable in the sequence as "strongest", but this seems to be an attributed rather than objective fact about the actual stress pattern: for example when Hollis (1983: 41) says that in the cursus "rais'd by a perfect mother" there is a 'slight and gradual dropping down in intensity from rais'd to perfect to mother" he is subjectively attributing an intensity drop. Similarly, Croll (1919: 46) says that where an earlier sequence of unstressed syllables is the same as a later one, the earlier one nevertheless "makes the effect of being greater", which is again an attributed characteristic. Another reason to think that the cursus is attributed to the text rather than an inherent form is that it is possible to dispute whether the cursus is present in particular cases; furthermore, there are intermediate or weak cases. Though the cursus comes at the end of a sense unit, this need not be at a line-ending, but can be mid-way through a line, and there is no requirement that a line end on a cursus. Thus the cursus has a loose relation to the line, but has no deterministic or fixed relation to it; again, this fits with its being an attributed form. 


\section{A note on punctuation}

Whitman's "punctuation is as loose as his morality", said a contemporary review (anon 1856), by which the reviewer was referring to the wide variety of punctuation marks used, and the tendency to use them just to separate paratactic sections, rather than to subordinate. Punctuation is relevant to poetic form because it constitutes evidence for form. Because Whitman's punctuation is so "loose", it provides loose evidence for the division of the text into sections, and particularly for the division of the line into parts; this looseness of evidence is exactly what we would expect if the sectioning and lineation are attributed rather than inherent. For example, Whitman's line may be divided into parts by four types of mark which do not appear line-finally: two-dots, three-dots, fourdots, and a dash (two-dots, dash and four-dots appear in the quoted text above). One function of punctuation is to cue performance, and Allen (1957: 415) suggests that the punctuation of Leaves of Grass indicates "caesural pauses" and "cadences" and "was an accurate index to the organic rhythm, the musical effects which the poet hoped to have brought out in the reading". Hollis (1983), who emphases the "orality" of the text, takes a similar view. But given that there are no explicit rules for reading Whitman's innovative punctuation, the interpretation of how to speak it can only be achieved via inference: this would be an attributed rather than an inherent function. Punctuation can also divide the text into parts irrespective of how it is spoken, and the punctuation does not consistently divide the text into Allen's rhetorical groups, or into parallel sections, so again, the punctuation has a loose relation to other kinds of structure, giving it an attributed function rather than an inherent one.

\section{Summary: the attributed forms in Leaves of Grass}

Whitman, citing Bunsen, said of language that "what is now fixed was once floating and moveable". Whitman interprets this to mean, "Thus individualism is a law in modern languages, and freedom also.... the words are not built in but stand loose, and ready to go this way or that" (Warren 1990: 45, citing Whitman 1978: 723). Whitman's conception of language in general thus fits with what he specifically did with poetic form, making it "loose and ready to go this way or that". We have seen that the various poetic forms can be characterised as attributed rather than inherent. This attributed status for poetic forms fits with the fact that they extensively interact with each other. Fabb (2009) argues that in metrical verse the interaction between distinct forms is strictly limited, such that distinct inherent forms only interact in pairs (rather than many-to-many interactions) and that this can be explained in terms of their being inherent forms, subject to some inherent metaconstraint. In contrast, the many-to-many interactions of the poetic forms in Leaves of Grass provide mutual but never fully consistent evidence for the other's existence as a form.

Having now characterized Whitman's various forms as attributed, in the next section, I consider how we might draw meaning from the use of attributed form in Whitman's poetry. 


\section{The meaning of attributed form in Leaves of Grass}

Leighton (2007: 243) describes “two ideas ... associated with the word 'form'. On the one hand it is a material construction, a house or tomb in which something is contained; and on the other, it is a body, nervous and feeling.... It is both a container and a content." Though Leighton rarely discusses poetic form as manifested by lineation, meter, rhyme, parallelism etc., when she does talk about these types of form, she sees them as having both a structural role and a symbolic meaning. Thus Yeats's metrical feet also stand in some sense for bodily feet. Such an understanding of form fits with Whitman's conceptualization of the forms of his poetry as symbolic manifestations, and in particular as manifestations of the body. In this section I consider how the attributed status of form Whitman's poetry contributes to the symbolism of the form.

Bucke (1883: 156), probably speaking with Whitman's consent or guidance, said of the title of Leaves of Grass that "properly understood, the words express what the book contains and is". The form of the text is not only an attributed meaning of the text but is itself evidence for the attribution of further meanings to the text. In order for any form to enter into an inference it must first be expressed as the content of a thought about the text, and thus must be a kind of attributed form. Thus in sound symbolism it is not the sounds themselves which are symbolic, but types of sound-form as attributed to the text: a recognition of sound symbolism does not require an understanding of the actual phonetic or phonological form of sound, but usually an explicit attribution of certain sound qualities to parts of the text such as "hard sounds" or "soft sounds" or "sibilant sounds" or "hissing sounds", and so on. The same is true of pattern poems (Higgins 1987), where lengths of lines and arrangements of lines draw very rough pictures of objects; for example, Herbert's "Easter Wings" loosely resembles an angel's wings. Here we must recognize the existence of lines as a characteristic of the text, in order to interpret the arrangement of lines as meaningful. Even if lines are inherent in a poem, they must also be explicitly attributed as forms of the text in order to explicitly incorporate them into an inferential process by which the form is assigned a symbolic meaning.

Poetic form can be attributed to Leaves of Grass in two significant ways. First, the poem is in lines, and moreover a new type of line, defined in complex ways relative to other attributed forms, as a type of attributed form. Second, all the attributed forms hold loosely (as is generally true for attributed form). Both of these aspects of poetic form relate to the meaning of the title. We begin with "grass", which symbolizes some of Whitman's core meanings: it is democratic because it is variety in collectivity, the same and yet varied, and this is also a characteristic of the lines themselves. It is also a context for lounging, thus fitting with the looseness of the form and of the looseness of relations between forms: "I loafe and invite my soul, / I lean and loafe at my ease .... observing a spear of summer grass." Because "all flesh is grass" (noted by anon 1856) the grass emerges from everyone's body, another type of democracy. This meaning is further enhanced by Whitman's interest in Ancient Egypt, and perhaps his selfidentification as the buried Osiris emerging from the ground as leaves of grass (Tapscott 1978: 51). Here we see two ideas merged: the idea of the author 
manifested as the text (it is "a song of myself") along with the author as all people, just as grass is a collective of blades, not just a single blade.

If we turn now to the word "Leaves" we can take this to have the conventional meaning of "pages" as seen in titles such as Fern Leaves from Fanny's Portfolio, an 1853 collection by his acquaintance Sara Payson Willis (Folsom and Price 2005: 61). Given the Egyptian connections, the pages also perhaps aspire to be sheets of papyrus which, manufactured from sedge, are literally leaves of grass. On the other hand, the leaves are also the lines. Whitman says, "Or I guess it [grass] is a uniform hieroglyphic, / And it means, Sprouting alike in broad zones and narrow zones, / Growing among black folks as among white," (1855: 16). This allows us to read the lines themselves as leaves of grass: broad and narrow and even black and white might be taken as terms describing the look of the lines on the page itself. If we take the lines as leaves of grass, then we must take some of them as bent leaves of grass (when the line is too long for the width of the page), and Whitman also says "Tenderly will I use you curling grass," (1855: 16), and "limitless are leaves stiff or drooping in the fields" (1855: 16). But more generally we can take "the uniform hieroglyphic" as a way of describing the need to interpret every aspect of the text (including its form).

In this sense, it is worth asking whether the various attributed forms of the text are premises in an inference whose conclusion is "democracy". Most obviously in the first edition, the forms as sections of text tend to be adjacent to one another, rather than one subordinated to another. The punctuation which is used tends to create juxtaposition between adjacent items rather than subordinate one to another. Only in later editions do parentheticals introduce a way of subordinating sections of the text within other sections. The rhetorical groups and parallelisms are juxtaposed sequences of equivalent items. Unlike metrical verse, one part of the line is not characteristically more regular than another, because the rhythmic cursus can appear anywhere in the line. Unlike regulated forms such as the English sonnet with its final couplet, sequences of lines do not contain "special" lines; the stanzas of Leaves of Grass are variable in length and often do not build up to any specific climax. The forms are communicated in a consistent and even manner throughout the text, none having priority over any other: the forms are meanings which the text produces as a "uniform hieroglyphic". For form to be meaningful in these ways as manifestations of democracy, form must itself be a meaning, attributed to the text.

\section{Conclusion}

The distinction between two fundamentally different kinds of poetic form inherent and attributed - is rarely explicitly formulated in literary or linguistic studies. The types of poetic form discussed in this paper are generally treated as unproblematic in literary studies, and while linguistic approaches to literature generally argue for inherent poetic form, the distinction between forms which are inherent and those which are not (i.e., attributed) is not discussed. The various poetic forms of Leaves of Grass all hold of the text solely by virtue of being attributed to the text, as the content of inferences for which the text 
provides evidence. Because the various forms interact with each other, they mutually strengthen the evidence for their existence. At the same time because none of the forms are inherent, none of the poetic forms of the text is built on a certain foundation; all can hold only with some degree of uncertainty. Furthermore, because the attributed forms are meanings of the text, they can be taken into account by further inferential procedures, allowing the form itself to symbolize the meanings of the text. Leaves of Grass combines attributed forms in new and perhaps unique ways. But even if it is unique in its combinations of forms, the book illustrates the general ways in which form holds in many other poetic texts in the English language. In particular it illustrates how in nonmetrical texts the various poetic forms are often attributed rather than inherent. By understanding that form can be a kind of meaning, we can find a path between form and meaning and a way of understanding how form can have all the complex characteristics of a meaning. This approach thus opens up significant possibilities for the formal analysis of English language texts in the post-metrical tradition for which Whitman was a pioneer.

\section{Acknowledgements}

Thanks to Faye Hammill, Elspeth Jajdelska, Gary Thoms, Stefano Versace, and the editors of this issue, for comments.

\section{References}

Allen, Gay Wilson (1933). Biblical Analogies for Walt Whitman's Prosody. Revue Anglo-Americaine, x: 490-507.

Anon (1856). "[Review of Leaves of Grass (1855)]." The Washington Daily National Intelligencer (18 February 1856): 2. Whitman Archive ID anc.00019.

Bucke, Richard Maurice (1883). Walt Whitman. Philadelphia, David McKay.

Croll, Morris W. (1919). The Cadence of English Oratorical Prose. Studies in Philology 16(1): 1-55.

Fabb, Nigel (1997). Linguistics and Literature. Language in the Verbal Arts of the World. Oxford: Blackwell.

Fabb, Nigel (1999). Verse Constituency and the Locality of Alliteration. Lingua 108: $223-245$.

Fabb, Nigel (2002). Language and Literary Structure: The Linguistic Analysis of Form in Verse and Narrative. Cambridge: Cambridge University Press.

Fabb, Nigel (2009). Formal Interactions in Poetic Meter. Versatility in Versification: Multidisciplinary Approaches to Metrics. Edited by Tonya Kim Dewey and Frog, 147-165. New York: Peter Lang.

Fabb, Nigel, and Morris. Halle (2008). Meter in Poetry: A New Theory. Cambridge: Cambridge University Press. 
Folsom, Ed, and Kenneth M. Price (2005). Re-Scripting Walt Whitman. An Introduction to his Life and Work. London: Blackwell.

Golston, Chris and Tomas Riad (2000). The Phonology of Classical Greek Meter. Linguistics 38(1): 99-167.

Hanson, K., and Kiparsky, Paul (1996). A Parametric Theory of Poetic Meter. Language 72(2): 287-335.

Hayes, Bruce and Claire Moore-Cantwell (2011). Gerard Manley Hopkins's Sprung Rhythm: Corpus Study and Stochastic Grammar. Phonology 28: 235-282.

Higgins, Dick (1987). Pattern Poetry. Guide to an Unknown Literature. Albany: State University of New York Press.

Hollis, C. Carroll (1983). Language and Style in Leaves of Grass. Baton Rouge: Louisiana State University Press.

Leighton, Angela (2007). On Form. Poetry, Aestheticism, and the Legacy of a Word. Oxford: Oxford University Press.

Mitchell, Roger (1969). A Prosody for Whitman? PMLA 84(6): 1606-1612.

Norman, William M. 1980. Grammatical Parallelism in Quiche Ritual Language. Proceedings of the Sixth Annual Meeting of the Berkeley Linguistics Society (1980), pp. 387-399

Saintsbury, George T. (1910). A History of English Prosody. Vol. III. From Blake to Mr. Swinburne. London: Macmillan and Co.

Tapscott, Stephen J. (1978). Leaves of Myself: Whitman's Egypt in 'song of Myself" American Literature 50(1): 49-73.

Warren, James Perrin (1990). Walt Whitman's Language Experiment. University Park: Pennsylvania State University Press.

Whitman, Walt (1855). Leaves of Grass (Page images available at the Walt Whitman archive, edited by Ed Folsom and Kenneth M. Price.)

Whitman, Walt (1881). Leaves of Grass (1881-2 edition: Page images available at the Walt Whitman archive, edited by Ed Folsom and Kenneth M. Price.)

Whitman, Walt (1978). Daybooks and Notebooks III. ed. Willia White. New York: New York University Press. 